\title{
Air quality, atmosphere, and health
}

\author{
An international journal
}

\author{
Jonathan M. Samet • Yong S. Chung
}

Received: 18 April 2008 / Accepted: 21 April 2008 /Published online: 24 May 2008

(C) Springer Science + Business Media B.V. 2008

Selecting the name for this new journal proved challenging. We wanted a title that would reflect the breadth of scientific research on the atmosphere, atmospheric pollution, and health and we wanted researchers and readers to be aware of our goal of having contributions from throughout the world. In its few words, Air Quality, Atmosphere and Health signals the intended broad scientific reach of the journal. The subtitle, "An International Journal," speaks of our intent to publish research from throughout the world, reflecting the global relevance of research on the topics that the journal will cover. While some problems of atmospheric pollution and related health concerns are local, many are regional, national, and transnational; we also seek to cover research findings from developed and less developed countries. Many developing countries are facing new problems of atmospheric contamination as they rapidly industrialize, increase motor vehicle use, and expand electric power generation. Activities in all countries are of increasing importance to atmospheric contamination with greenhouse gases.

Many scientific disciplines address topics fitting within the scope of Air Quality, Atmosphere and Health: atmospheric sciences including air pollution measurement and control, aerosol sciences, atmospheric chemistry, and modeling; public health sciences including epidemiology, toxicology, and exposure assessment; environmental ecology; policy-related fields, such as environmental economics, risk assessment, and environmental policy. We intend to publish papers in these and other areas relevant to the

J. M. Samet $(\bowtie) \cdot$ Y. S. Chung

Department of Epidemiology, Johns Hopkins Bloomberg

School of Public Health, 615 North Wolfe Street,

Baltimore, MD 21205, USA

e-mail: jsamet@jhsph.edu journal's purpose: “...a multidisciplinary journal that focuses on atmospheric consequences of human activities and their implications for human and ecological health." We recognize that there are already many disciplinespecific journals in this area. This new journal has the goal of serving as a forum where researchers can find research results from other disciplines relevant to the questions that they are addressing. Through editorial commentary that relevance will be made clear.

Research carried out on human contamination of the atmosphere has the end purpose of characterizing the resulting problems and informing the development and implementation of solutions to the problems. The evidence needed for this purpose comes from the range of scientific researchers that we seek as contributors to the journal. Atmospheric pollution is typically investigated with careful measurements and modeling; health effects of pollution are investigated with exposure assessment, epidemiology, and toxicology; and control strategies are developed with the use of models, engineering and technology, and air quality policies. Human health and ecological risk assessment and cost-benefit analysis may be used to motivate action and to guide choices of control measures. Air Quality, Atmosphere and Health will publish significant research from these and other disciplines on the many threats to human and ecological health worldwide and on approaches to controlling them.

Human activities affect the atmosphere on scales that range from local to global. In the past, research on human and ecological health was largely focused at local, most often urban, and regional levels. Some of the first warnings about air pollution and health came from dramatic episodes of mortality in the Meuse Valley, Los Angeles, Donora, London, and elsewhere; these episodes were driven by largely uncontrolled industrial sources, stagnant weather 
conditions, and local terrain. Even photochemical oxidant pollution was once considered a local problem, limited to the Los Angeles air basin where it was first described in 1950 by Haagen-Smit. Now, photochemical pollution is widespread throughout the United States and other countries and its control requires regional management approaches. Longrange transport of air pollution masses may affect human and ecological health at sites far from the pollution sources. "The Asian Brown Cloud," for example, covers massive portions of the continent over all seasons and may be leading to melting of glaciers and snow in the high mountains and of ice over the Arctic Ocean. Scientists have also observed that trans-oceanic air pollutants and gases from North America affect background levels of air pollution in western Europe and contribute to partial melting of ice in Greenland.

Of course, one of the most concerning and widely discussed consequences of contamination of the atmosphere is global warming from greenhouse gas emissions. Address- ing climate change is one of the top priorities of the United Nations; to coordinate efforts they have set up a blueprint for action to sustain "unprecedented momentum" to fight global warming. The consequences are projected as sweeping, with climate change having direct and indirect impacts on human and ecological health. Air Quality, Atmosphere and Health seeks papers on this topic as well, particularly reports of findings that transect the boundaries of the diverse research disciplines contributing to our understanding of global warming.

We hope that papers published in Air Quality, Atmosphere and Health will contribute to finding solutions for the consequences of atmospheric contamination by human activities. As editors, we intend to solicit and publish reviews and commentaries that will add to the impact of research papers. We will need guidance and feedback from our contributors and readers. We look forward to receiving your papers and your constructive comments. 